\title{
Characterisation of natural Zeolite and the feasibility of cations and anions removal from water
}

\author{
G. Badalians Gholikandi ${ }^{1}$, H. R. Orumieh ${ }^{2} \&$ H. R. Tashauoei ${ }^{3}$ \\ ${ }^{1}$ Power and Water University of Technology (PWUT), \\ Water Research Institute (WRI), \\ Water and Wastewater Research Centre (WWRC), Tehran, Iran \\ ${ }^{2}$ Pars arianab Consulting Engineers, Isfahan, Iran \\ ${ }^{3}$ National Water and Wastewater Company (NWWC), Tehran, Iran
}

\begin{abstract}
There are great resources of natural zeolite in Iran. Zeolite, an inorganic ion exchanger, may be used as a suitable technical-economical solution for water treatment in many regions in Iran.

In this research, the characterization of Zeolite in the east region of the country and the feasibility study for removal of hardness, cations and anions was investigated as follows: (1) determination of Zeolite composition and type by using X-Ray Fluorescence (XRF), thermal analysis and infrared spectrometer methods. (2) determination of cation exchange capacity (CEC) and its impact on water hardness reduction. Determination of isotherm curves for $\mathrm{Fe}, \mathrm{Cr}, \mathrm{Al}, \mathrm{Bi}$, $\mathrm{Cd}, \mathrm{Mn}, \mathrm{Ca}, \mathrm{Mg}, \mathrm{Ag}, \mathrm{Ni}, \mathrm{Zn}, \mathrm{Cu}, \mathrm{Pb}$ and their disposition to Zeolite phase, also determination of removal rate of the mentioned cations in analyzed water samples. (3) Zeolite structure rectification by using surfactant (HDTMA) for anions removal.
\end{abstract}

Keywords: natural Zeolite, characterization, water treatment, cations and anions removal.

\section{Introduction}

Using new materials for economical-technical optimization of water treatment process is always under close investigation. 
Zeolite is a microporose rigid crystalline with pore, cleft and a micro canal diameter of 3-10 angstrom. It is an inorganic ion exchanger belonging to crystalline alum silicates classification and its crystalline lattice consists of $\mathrm{SiO}_{4}$ and $\mathrm{AlO}_{4}$ units with common oxygen. The absence of one positive valence because of existing 3 valence aluminium ions causes access possibility of alkaline ions. It must be mentioned that these ions don't have a stable condition in crystalline lattice and their exchange with cations is probable. Ten-twenty percent of Zeolite's weight relates to existing water. All or part of this water can be removed by heating up to $350^{\circ} \mathrm{C}$ without destructing of the crystalline lattice.

The applied formula of Zeolite is:

$$
\begin{aligned}
& \mathrm{M}_{2 / \mathrm{n}} \mathrm{O} \cdot \mathrm{Al}_{2} \mathrm{O}_{3} \cdot \mathrm{YSiO}_{2} \cdot \mathrm{ZH}_{2} \mathrm{O} \text { or } \mathrm{M}_{\mathrm{x} / \mathrm{n}}\left[\left(\mathrm{AlO}_{2}\right)_{\mathrm{x}}\left(\mathrm{SiO}_{2}\right)_{\mathrm{y}}\right] \cdot \mathrm{ZH}_{2} \mathrm{O} \\
& \mathrm{M}=\text { metal cation, } \mathrm{n}=\text { cation's valence, } \mathrm{x}=2-10, \mathrm{y}=2-7 \text {. }
\end{aligned}
$$

In general, Zeolite consists of following three main segments: (1) aluminium silicate framework (in bracket), (2) vacuous pores of crystalline lattice containing exchangeable cations, (3) water molecules as a surrounder phase. The natural and synthetic Zeolites are categorized due to secondary structural units including $\mathrm{S}_{4} \mathrm{R}, \mathrm{S}_{6} \mathrm{R}, \mathrm{D}_{4} \mathrm{R}, \mathrm{D}_{6} \mathrm{R}, \mathrm{T}_{5} \mathrm{O}_{10}, \mathrm{~T}_{8} \mathrm{O}_{16}$ and $\mathrm{T}_{10} \mathrm{O}_{20}[1,2,4,5]$. One of the major sources of Zeolite is located in the east of Iran (fig. 1).

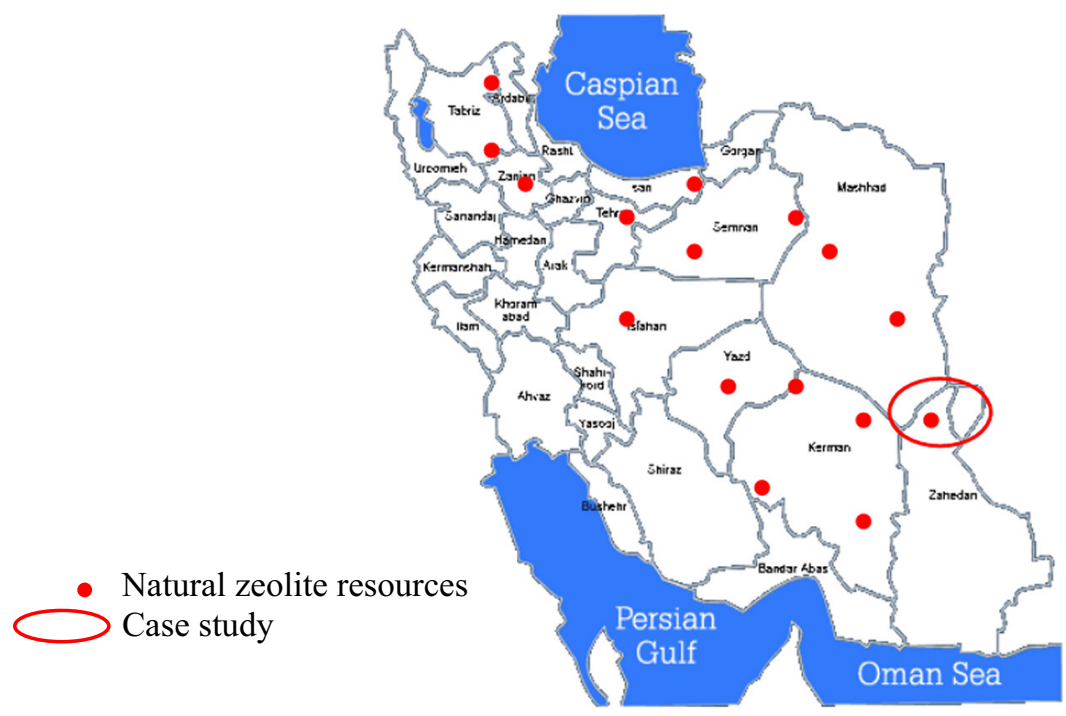

Figure 1: The location of Zeolite sources in Iran [3]. 


\section{Characterization of natural Zeolite}

The characterization of investigated natural Zeolite resulted from the following methods: (1) Thermal weighting analysis (fig. 2). (2) Ultra red analysis with SHIMADZVIR-470 spectrometer (fig.3). (3) X-Ray D analysis (fig. 4). The results are showing a certain conformity with Natrolite $\left(\mathrm{Na}_{4} \mathrm{Al}_{4} \mathrm{Si}_{6} \mathrm{O}^{20} 4 \mathrm{H}_{2} \mathrm{O}\right)$ [6].

\section{Hardness removal}

Due to the importance of water hardness as a quality parameter, particularly for groundwater resources, its reduction via natural Zeolite was investigated.

\subsection{Materials and method}

Two gram agitated Natriumzeolite in $100 \mathrm{~mL}$ water and 24 hours detention time in a shaker was used for determining of total, temporary and permanent hardness via EDTA titration method.

\subsection{Results}

The results show considerable efficiency (ability) by using Zeolite for hardness removal (fig. 5).

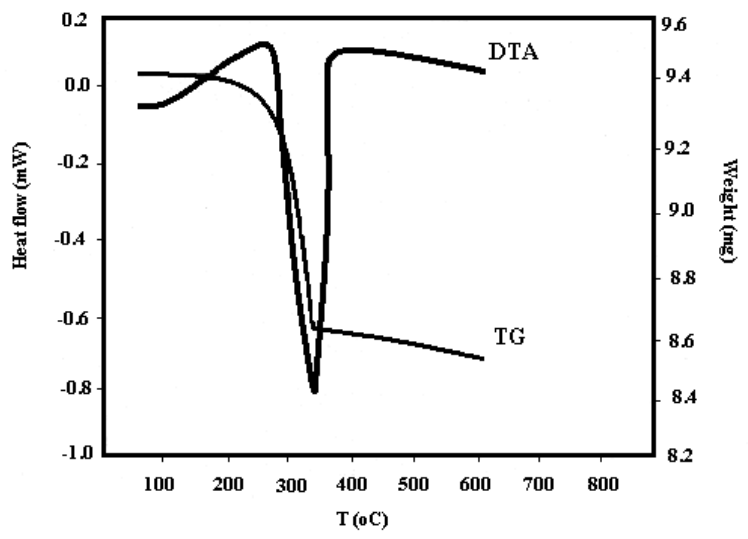

Figure 2: Thermal weighting analysis diagram of investigated Zeolite [6]. 


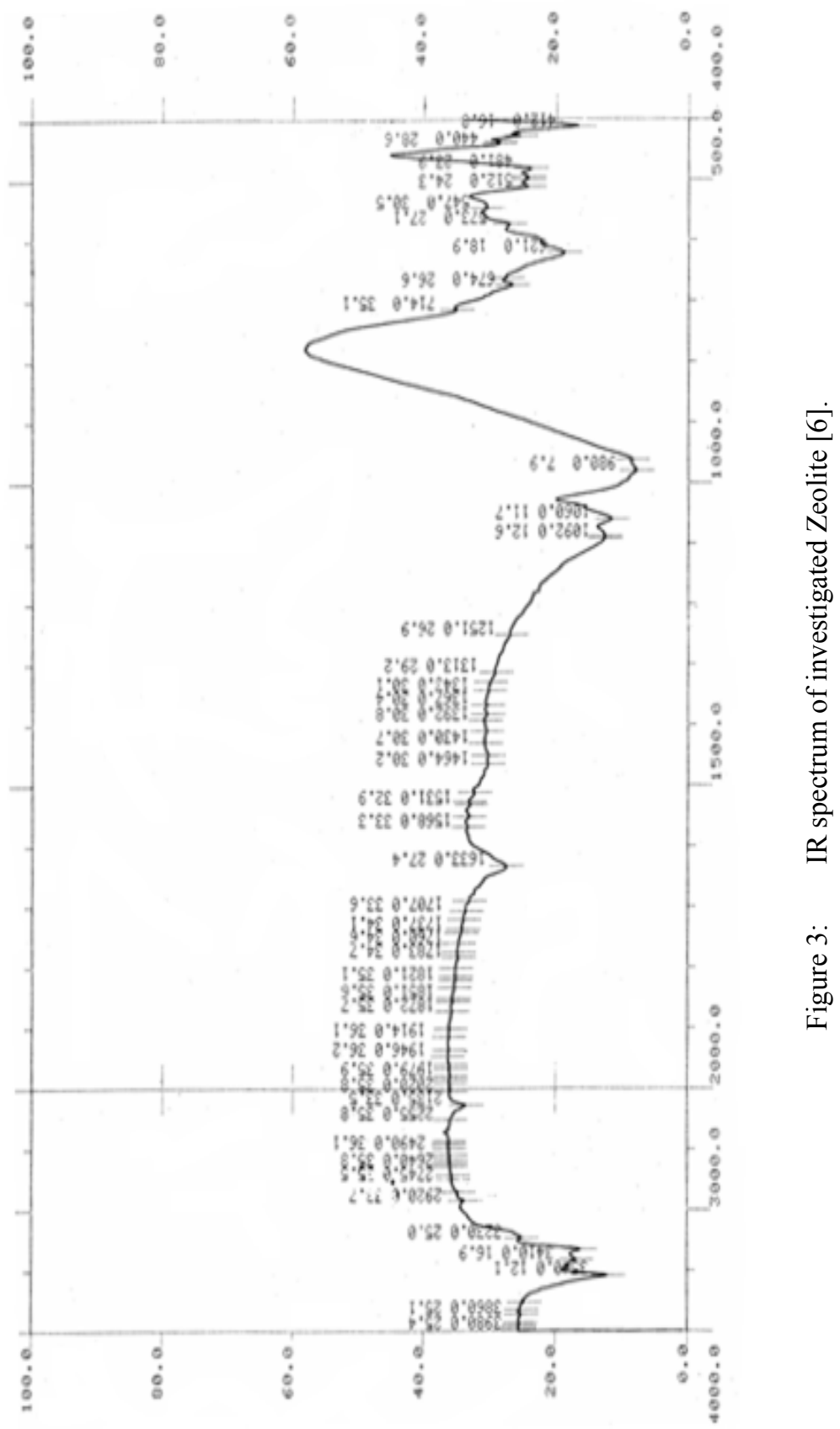




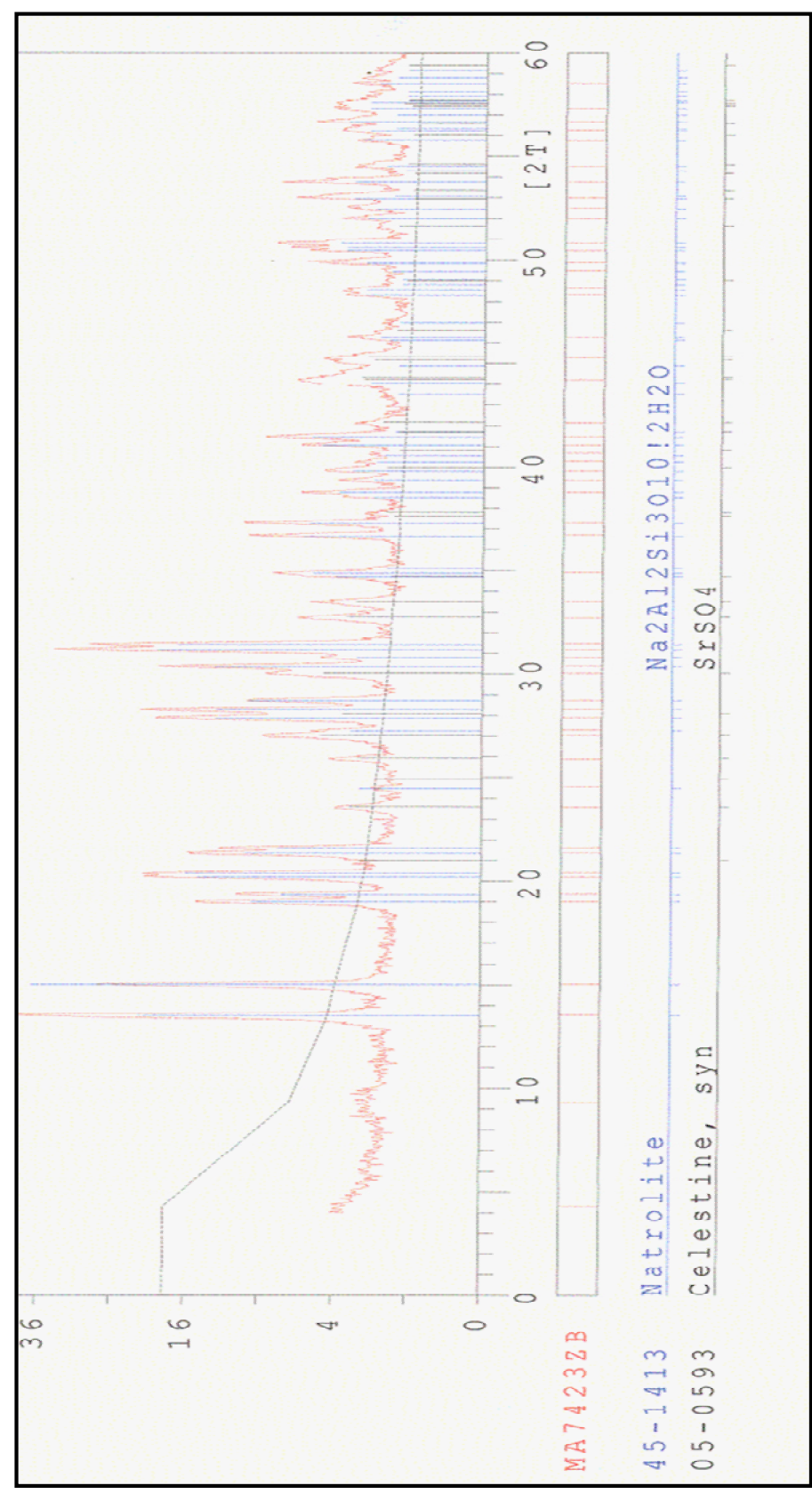

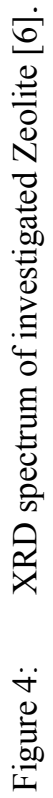




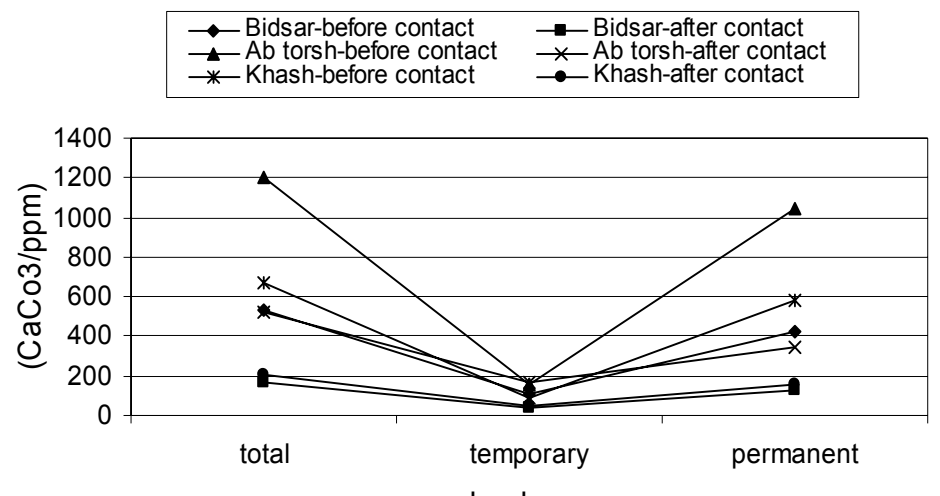

hardness

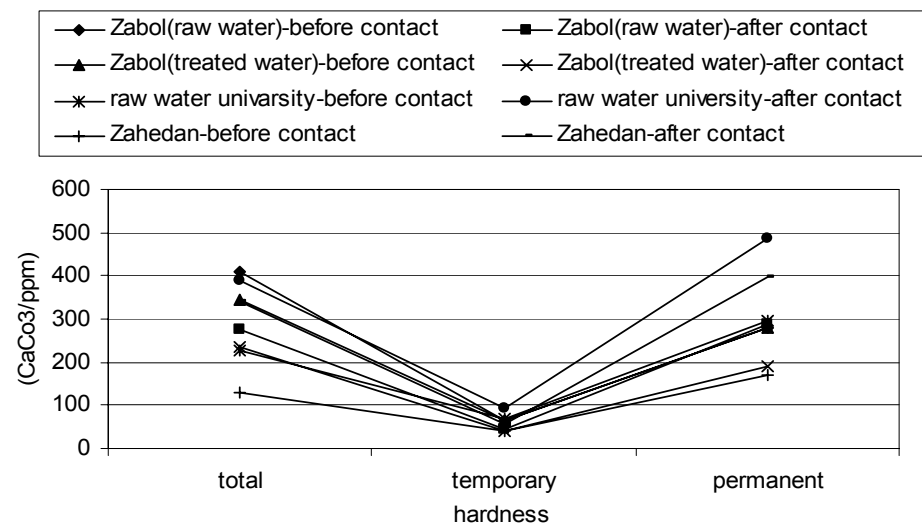

Figure 5: $\quad$ Water hardness removal, 7 different water samples [6].

\section{Cations removal}

\subsection{Materials and method}

Zeolite samples, mesh 80, were used after mixing with 4M Natrium chloride for 24 hours and decantation of upsides liquid. After washing the Zeolite with distilled water (2 times distillation) and removing remaining salt, and then drying, the process was performed. Considering the adsorption coefficient importance of each adsorbent phase, the adsorption isotherms were determined, due to Freundlich isotherm. For this purpose, 1 gram of Zeolite was mixed with $50 \mathrm{~mL}$ of liquid of different analytes with different concentrations for 48 hours. The remaining concentration of analyte was determined via an atomic adsorption spectrometer. 

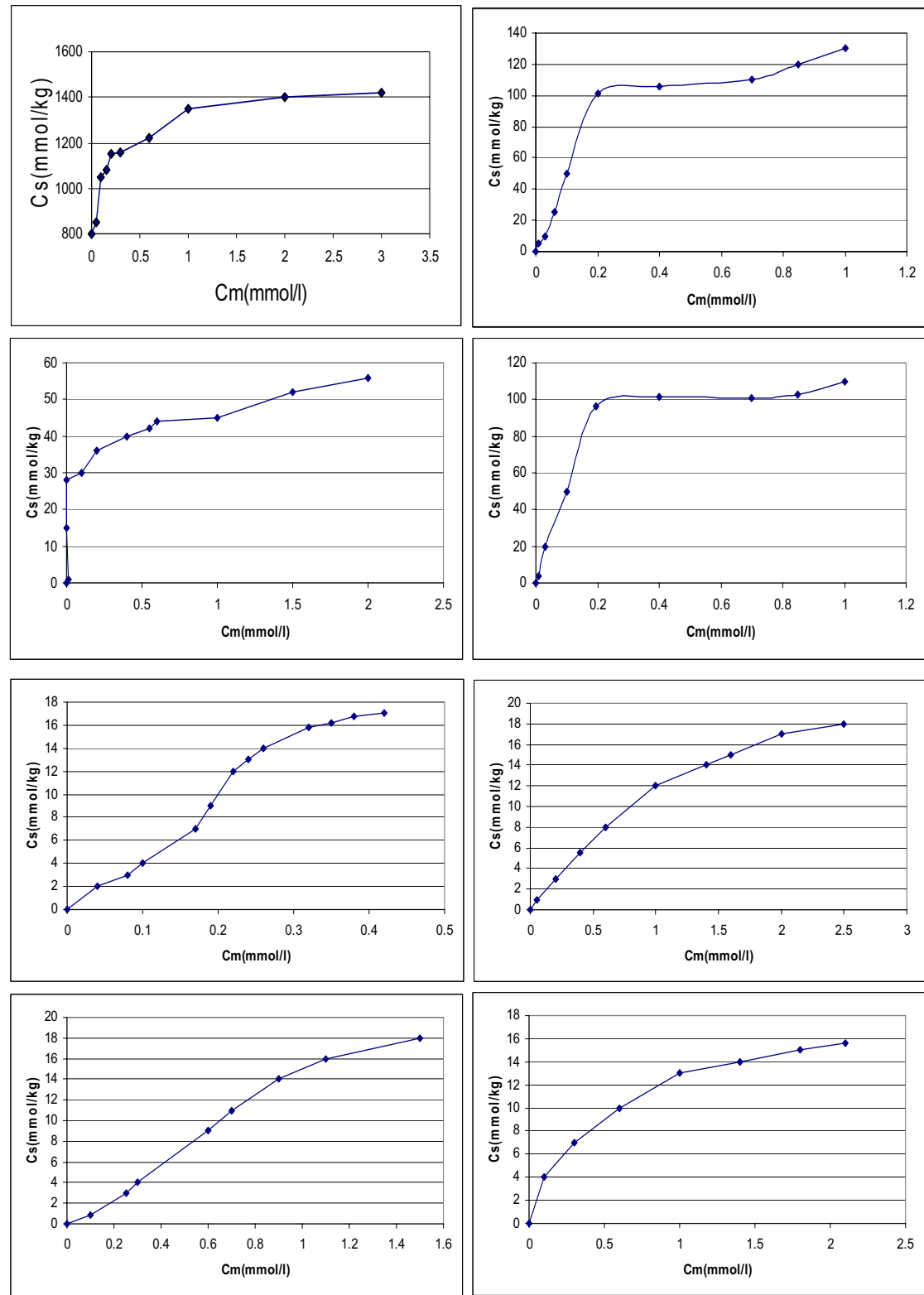

Figure 6: Isotherm curves of investigated cations, in order $\mathrm{Fe}, \mathrm{Cr}, \mathrm{Bi}, \mathrm{Al}, \mathrm{Cd}$, $\mathrm{Mn}, \mathrm{Ca}, \mathrm{Mg}, \mathrm{Pb}, \mathrm{Ni}, \mathrm{Ag}, \mathrm{Zn}$, and $\mathrm{Cu}[6]$. 
234 Computational Methods and Experiments in Materials Characterisation IV
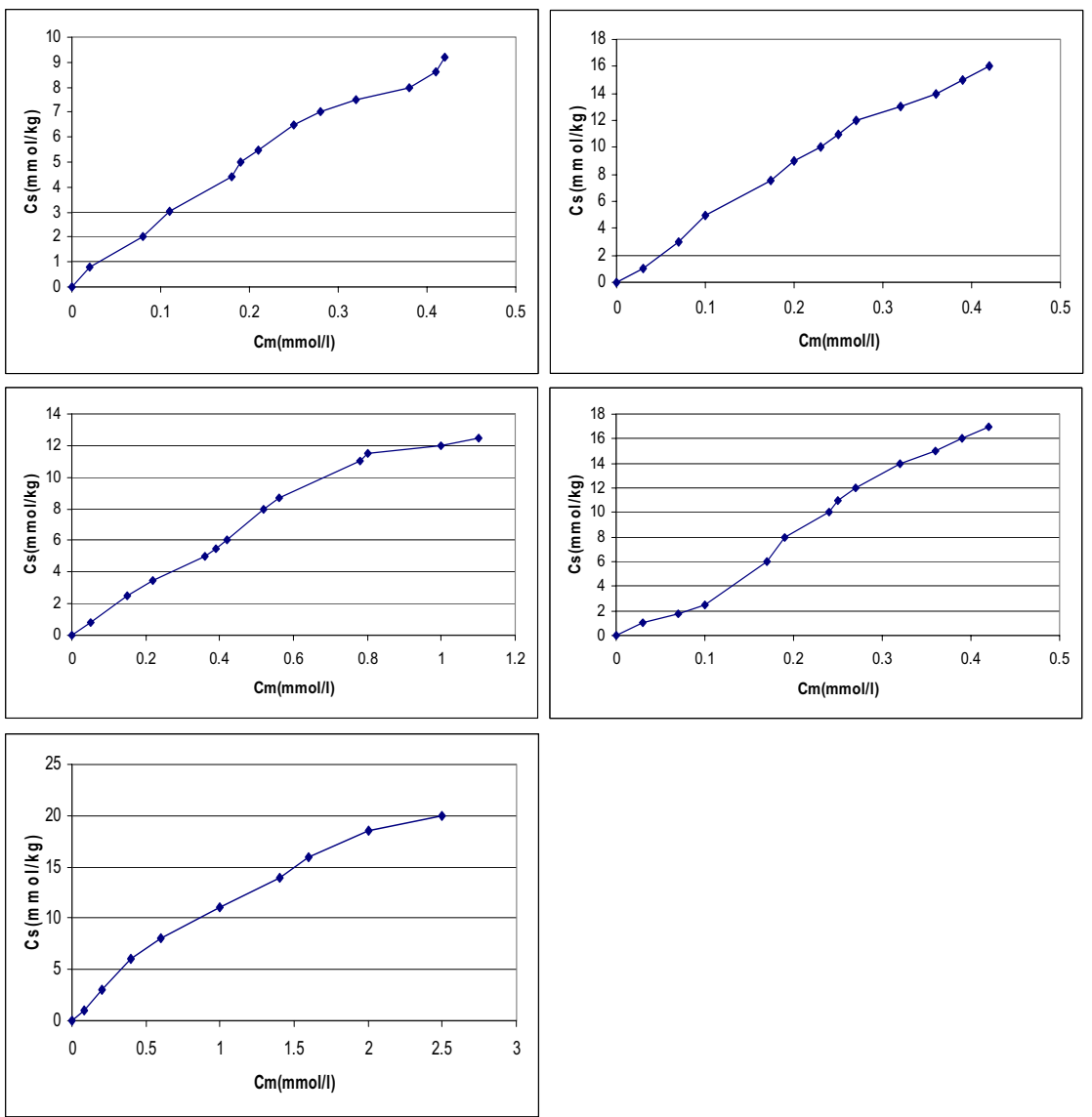

Figure 6: Continued.

\subsection{Results}

The obtained isotherm curves are shown in Figure 6. Due to the results, the classification of different cations in accordance with their affinity to Zeolite is: $\mathrm{Fe}^{3+}>\mathrm{Cr}^{3+}>\mathrm{Al}^{3+}>\mathrm{Bi}^{3+}>\mathrm{Cd}^{2+}>\mathrm{Mn}^{2+}>\mathrm{Ca}^{2+}>\mathrm{Mg}^{2+} \sim \mathrm{Ag}^{2+} \sim \mathrm{Ni}^{2+} \sim \mathrm{Zn}^{2+}>\mathrm{Cu}^{2+}>$ $\mathrm{Pb}^{2+}>\mathrm{Hg}^{2+}$.

Considering high concentrations of heavy metals like $\mathrm{Fe}, \mathrm{Cr}$ and others in several groundwater resources, it is an economical-technical advantageous possibility to use natural Zeolite for groundwater treatment.

\subsection{Cations removal from water}

\subsubsection{Materials and method}

An amount of $10 \mathrm{gr}$ Zeolite was added to $100 \mathrm{~mL}$ synthetic water sample with different cations (concentration of each cation equals $100 \mathrm{ppm}$ ). After 24 hours 
of mixing and thereafter filtrating, the remaining concentration of each cation was determined via an atomic adsorption spectrometer.

\subsubsection{Results}

The results are shown in Figure 7. Due to the results, the investigated natural Zeolite is particularly appropriate to remove $\mathrm{Fe}, \mathrm{Bi}, \mathrm{Cr}, \mathrm{Mg}$ and $\mathrm{Ca}$ cations.

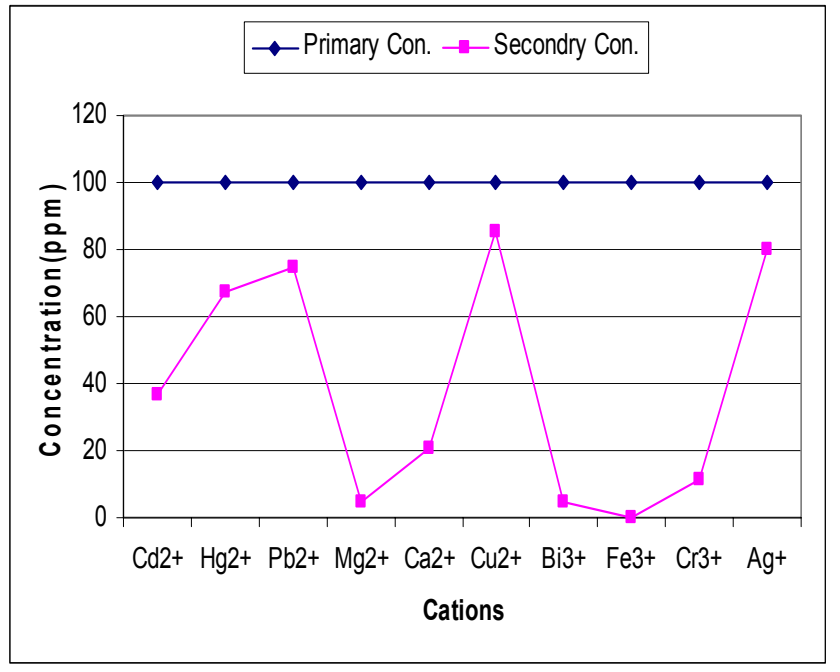

Figure 7: Cations removal abundance from synthetic water sample by using investigated Zeolite (Natrolite) [6].
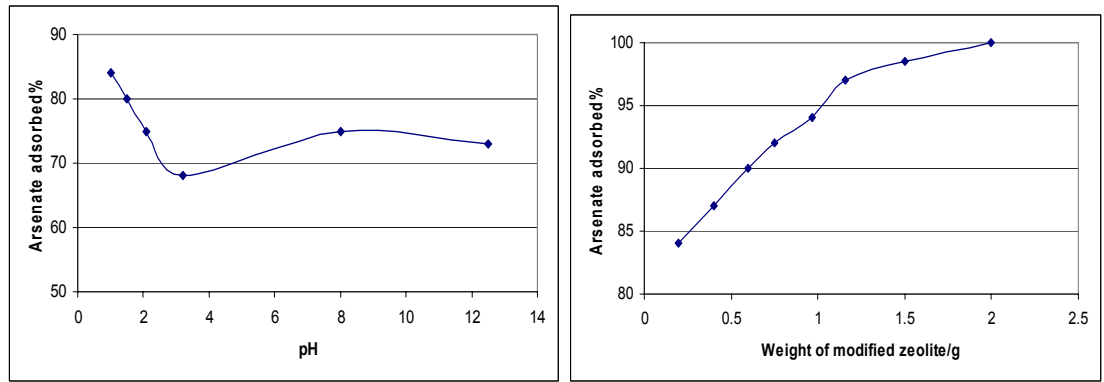

Figure 8: $\quad$ Arsenic removal depends on $\mathrm{pH}$ and required Zeolite [6].

\section{Anions removal from water}

Considering the existing active agent in anionic structure of Zeolite, cations can only be adsorbed. Hence, it must be remediated by using surfactants, especially HDTMA-bromide for organic compounds and inorganic toxic anions removal for instance chromate, nitrate, arsenate, selenate and sulphate. 


\subsection{Materials and method}

In each phase, 10 gr Zeolite was mixed with $40 \mathrm{~mL}$ HMNDA compound(N,N,N,N',N',N'-hexamethyl-1/9-nonanediammonoumi bromide, 2/72.10 molar) in 65 percent ethanol liquid. After 48 hours detention time in mixer, the Zeolite's colour was changed from white to grey. The remediate material must be removed via washing by water which is distilled twice and ethanol liquid $(65 \%)$ for several times. Then, this Zeolite was made dry (24 hours in open air).

\subsection{Results}

Since groundwater resources contain arsenic, especially in the West and Northwest of Iran, the removal of arsenic ions was investigated. The results are shown in figure 8 and show that the optimized $\mathrm{pH}$ equals $1.5-2$ and required Zeolite for removal process equals $2 \mathrm{gr}$.

\section{Conclusion}

Natural Zeolite can be used as a suitable material for groundwater treatment. The investigated natural Zeolite is characterized as Natrolite. It is concluded that this Zeolite has a considerable ability to remove hardness, 3 valence cations and also it is particularly appropriate to remove anions like arsenic that depends on $\mathrm{pH}$ and HMNDA.

\section{Acknowledgement}

This study was supported by the Sistan and Belouchestan Water and Wastewater Company (SBWWC) and National Water and Wastewater Company Iran (NWWC).

\section{References}

[1] Badalians Gholikandi, G. (2003). Water chemistry, Now-pardazan publ., Tehran-Iran.

[2] Bae, M.N., Song, M.K., Kim, Y., Seff, K. (2003). Micro porous and Mesoporous Materials 63, 21.

[3] National Iranian Geology Institute (2008). www.ngdir.ir.

[4] Covarrubias, C., Garci'a, R., Arriagada, R., Ya'nez, J., Garland, M.T.(2006). Micro porous and Mesoporous Materials 88, 220.

[5] Kadono, T., Chatani, H., Kubota, T., Okamoto, Y. (2006). Micro porous and Mesopouros Materials 66.

[6] Sistan and Bilouchestan Water \& Wastewater Comp., (2008). Natural Zeolite for groundwater treatment, Research Report. 